\title{
Enriched Digital Catalogues: A Multi-study Approach: An Abstract
}

\author{
Ingrid Poncin and Marion Garnier
}

\begin{abstract}
Facing digitalization and ecological considerations, catalogues are at a crossroad. Technology now allows digital versions of catalogues that can be enriched, thanks to videos, pictures or rich media tools. As literature highlights the similarity between websites and digital catalogues, what is the point to develop both and to display an online version of the catalogue along the website? What is the point for consumers in using one or the other? What is the utility and experience offered by the digitalized catalogue, as compared to the website? What is the effect of enriching online catalogues? This research deals with understanding stakes of the digital version of a paper catalogue, especially when enriched, as compared to a website and adopts a dual perspective tackling utilitarian and experiential elements and outcomes. Two experimental studies were conducted in order to examine the potential adoption determinants for the digital catalogue and then to examine differences between website and digital catalogues in terms of utilitarian and hedonic values, their impact on behavioural intentions and the potential impact of types of enrichments. Results mainly highlight potential differences between websites and digital catalogues, whether enriched or not, in adoption determinants as well as in values driving behavioural intentions.
\end{abstract}

\footnotetext{
I. Poncin $(\bowtie)$

Université Catholique de Louvain, Mons, Belgique

e-mail: ingrid.poncin@uclouvain.be

\section{Garnier}

Grenoble Ecole of Management, Grenoble, France

e-mail: marion.garnier2@grenoble-em.com
} 